\title{
Educational Triage and Ability-Grouping in Primary Mathematics: A Case-Study of the Impacts on Low-Attaining Pupils
}

\author{
Dr Rachel Marks
}

Department of Education \& Professional Studies, King's College London, UK and School of Education, University of Brighton, $U K$

\begin{abstract}
This case-study, drawing on an unanticipated theme arising from a wider study of ability-grouping in primary mathematics, documents some of the consequences of educational triage in the final year of one primary school. The paper discusses how a process of educational triage, as a response to accountability pressures, is justified by teachers on the basis of shared theories about ability and potential. Attainment gains show that some practices associated with the triaging process work for the school, pushing selected pupils to achieve the Government target for the end of primary school. However, other practices appear to coincide with reduced mathematical gains for the lowest attaining pupils and a widening of the attainment gap. This case-study examines the mechanisms behind this, focussing on resource allocation and assumptions about learners and their potential. The paper suggests a need to create dissonance, challenging shared assumptions such as fixed-ability, which currently support triage processes.
\end{abstract}

Keywords: ability-grouping; educational triage; primary mathematics

\section{Introduction and Context}

Educational triage is a process of goods distribution whereby a number of linked practices are enacted to achieve a specified aim, usually related to maximizing attainment outcomes. This paper focuses on the process of educational triage in mathematics in the final year of one primary school: Avenue Primary ${ }^{1}$. Avenue Primary justified practices on the basis of widely held beliefs about ability and hence directed resources at pupils believed to have most potential to benefit. The triage process was enacted by bringing together a range of practices - many being common ability-grouping practices - with the intention of pushing as many pupils as possible to achieving the Government's target of Level 4 in the end of primary school tests. Managerial and teaching staff were open about engaging in a triaging process, highlighting, for example, the practice of allocating the strongest staff to pupils on the 'cusp' of achieving desired outcomes. However, these intentional practices also gave rise to unintended consequences. 
This paper examines the impacts of educational triage on the lowest attaining pupils in mathematics. It explores how practices associated with triage achieve the aim of increasing the number of pupils meeting Government targets, yet leave some - the lowest attaining pupils - with reduced mathematical learning experiences. This unintended consequence appears to coincide with an increase in the attainment gap. The paper draws on the experiences of pupils labelled low-ability ${ }^{2}$ in mathematics in the final year of primary school. As a case-study, it forms part of a wider research study into ability labelling in primary mathematics (Marks, 2012). Of particular import, this case-study is set within the English context where, as part of school accountability and performance management, all 11 yearolds are tested in mathematics at the end of primary school, with test results being high-stakes to schools.

Ability is a pervasive Discourse within England, particularly in mathematics where ability-grouping practices are commonplace. These include table groups (within-class grouping, common in primary schools), setting (between-class grouping for individual subjects) and streaming (ability-based classes formed across subjects). The use of abilitygrouping - particularly setting - is increasing in primary schools (Hallam \& Parsons, 2013). Selection practices are linked with policy changes and grounded in 'common sense' fixedability thinking where individual potential is thought to be immutable and easily determined (Marks, 2013).

Whilst the literature on ability-grouping in secondary mathematics is quite extensive (e.g. Boaler, 1997; Solomon, 2007; Wiliam and Bartholomew, 2004) particularly in terms of attainment and attitudinal outcomes across groups, the literature within primary mathematics is more limited. However, the wider research from which this case-study is drawn suggests that primary ability-grouping practices and their impacts essentially mirror the literature in secondary mathematics. This case-study uses a 'telling-case' to explore how Government 
targets and fixed-ability thinking come together to impact on practices, such as resource distribution, and how a shared Discourse is used to justify such practices.

\section{Conceptual Framework}

Within this study, ability, and its effects, are understood to be co-constructed through discourse. Discourse is used in educational research in various ways. This case-study takes the approach of Gee $(1999,2008)$. Gee makes a distinction between discourse and 'Big D' Discourse. Whilst discourse represents the actual language, as used, this language is usually embedded in social practices and may be specific to particular communities. It is this combination of language and social practices which Gee refers to as Discourse, seeing this as taking place within Discourse Communities. Teachers in a school would represent one such community. Within these Discourse Communities, sense-making takes place, allowing meaning to be constructed. By being part of sense making, Discourses are trying to deal with things that may be complex, paradoxical or contradictory. As part of this sense-making process social structures are produced and maintained.

\section{Discourses of ability}

Ability is a Discourse in Gee's 'Big D' sense. As used - both in schools and more broadly it acts as a shared theory within Discourse Communities to distribute, and justify the distribution of, educational goods. Ability has proven to be a particularly contentious Discourse, not least because it lacks solid definition, being "plagued by conceptual problems" (Howe, 1996, p. 40). Despite this complexity, the actual term ability is in widespread use in education, usually going unquestioned.

The dominant view of ability in schools - and perhaps particularly in mathematics - is as a fixed determinant of pupils' future attainment, relatively impervious to change. Through a long history, such beliefs have become elevated to the status of truths through the simple stories they tell and the appeal to a "basic human need to stratify society" (Kulik \& Kulik, 
1982, p. 619). These concepts have served to legitimise educational stratification by ability as a logical response and, drawing on Gee's understanding, a justified distribution of goods.

\section{Educational triage}

One manifestation of ability as a shared theory of goods distribution is seen in the process of educational triage in schools. Building on the medical crisis or battlefield model, triage entered educational literature over 30 years ago (e.g. Keenan \& VanHorn, 1979) to explain how schools make decisions around learning opportunities based on maximizing outputs, or survivors. The model obtained greater awareness through Gillborn and Youdell's (2000) study which used triage to explain how resources were targeted at pupils on the borderline of achieving targeted output measures at the age of 16 (the end of formal schooling at that time) in mathematics. Their study also highlighted how pupils below this threshold were left to flounder, resembling patients "without hope" (Gillborn \& Youdell, 2000, p. 134) in the medical model. Similarly, this medical model has been used in US studies examining the impact of the 2001 No Child Left Behind Act where schools have been found to divert resources towards "bubble kids" - those students near proficiency levels whilst giving no additional attention to students deemed unlikely to reach proficiency levels (Booher-Jennings, 2005; Neal \& Schanzenbach, 2010).

Triage processes illustrate how meaning making and shared theories - in this case about ability and the subsequent distribution of educational goods - play out in practice in Discourse Communities. A Discourse of ability provides teachers with an apparently legitimate way to manage limited resources for the greatest good. This case-study explores how this played out in one primary school where the Discourse Communities the staff were a part of led to specific decisions around the distribution of educational resources. It must be borne in mind that ability-grouping and triage processes take place within a policy context, in this case one of accountability in a climate where schools are increasingly subjected to target- 
setting and "output controls" (Gewirtz \& Cribb, 2009, p. 158). Pressures associated with audit and accountability undoubtedly influence how triage and other models of goods distribution play out in schools although discussion of this is beyond the scope of this paper.

In the context of this paper, triage is used as an over-arching term to refer to a set of practices implemented in Year 6 (the final year of primary schooling) at Avenue Primary to optimise outcomes in pupils' national test results in mathematics. These practices, which together form a triage process, built upon responses to accountability combined with ability as a theory of goods distribution, resulted in different groups of pupils receiving different educational experiences based on assumptions about pupils' potential. A triage model provides one way of understanding why teaching groups, or sets, are formed as they are, an indication that treatment may be different across sets, and a clear group to focus this casestudy on: low-attaining pupils in the bottom set (Set 4) below the threshold for enhanced provision.

\section{The Case Study}

Educational triage and the impact of this process on low-attaining pupils arose out of analysis conducted within the wider study rather than being under initial investigation (the emergence of this data and its relation to the wider study data corpus is set out below). As such the case may be thought of as an opportunistic choice. It is also a telling-case (Mitchell, 1984). The events discussed in this paper took place in a school, contextualized further below, where it would be reasonable, given the high socioeconomic status of the area, to expect that parents had the power to challenge practices which limited educational opportunities for some pupils. However, such a challenge did not occur. This lack of challenge may have, at least in part, been absent as parents inhabit Discourse Communities with similar shared theories as a result of the strong orthodoxy of ability within which the English education system sits. As such 
this case-study provides a strong telling-case applicable to contexts where actors - such as parents - have less power to challenge systems.

The aim of this case-study was to examine the experiences of pupils in the lowest ability set, triaged as below the threshold for targeted resources. This is approached through the research question: How do the lowest attaining pupils in primary mathematics experience educational triage? A case-study approach to this question allows exploration close to the participants and richly captures the complexity of the meaning and intentions behind participants' actions (Moore, Lapan, \& Quartaroli, 2012).

\section{Bounding the case}

This research is a single longitudinal case-study conducted over one academic year at one research site, drawn from a wider study of ability Discourses amongst teachers and students in primary classes. This section details the specific portion of the wider study under investigation, allowing the reader to understand how the elements of the study correspond.

\section{Research Site}

The wider study took place at two research sites, both primary schools in Greater London. This case-study draws on data from one site, Avenue Primary, selected as a 'telling-case'. The school has almost 700 pupils, with 35 teachers and 40 teaching assistants (low or unqualified assistants working alongside teachers in the classroom). This over-subscribed school is located in a popular commuter area with many parents in professional occupations. $10 \%$ of pupils (compared with $21 \%$ nationally) are eligible for free school meals. Avenue Primary has a strong reputation locally and parents see it as a pathway into selective secondary education. In the year of the study, $90 \%$ of pupils achieved Level 4 or above in their mathematics national tests (Level 4 is the Government's target for the end of primary education, with $79 \%$ achieving this nationally in the year of the study). 


\section{Participants}

Drawn from the wider study with 284 pupils, this case-study focuses on the 88 pupils in Year 6 at Avenue Primary. For mathematics, these 88 pupils were split into four unequally-sized ability sets as detailed in Table 1. This case-study focuses predominantly on the pupils in Set 4 in order to explore the experiences of pupils not expected to attain the Government target for the end of primary school.

\section{Table 1 here}

Three focal-pupils - Peter (high-achieving), James (middle-achieving) ${ }^{3}$ and Samuel (lowachieving) - were selected from Set 4 by the teacher to represent the attainment range. These pupils were interviewed individually, formed an interview focal-group and were the focus of classroom observations. All Set 1 and 4 teachers were included in the study. The teachers included (or referred to) in this case-study are: Mr Leverton (Year 6, Set 4 teacher), Mr Quinton (Year 6, Set 3 teacher), Mrs Jerrett (Year 4, Set 4 teacher) and Mr Iverson (Deputy Headteacher).

\section{Research methods}

The research from which this case-study is drawn used a mixed-methods approach. The research methods of the main study and the data drawn on in this case-study are outlined in Table 2.

Table 2 here

\section{Attainment tests}

A robust attainment test suitable for the full attainment range (developed by Brown, Askew, Hodgen, Rhodes, Millett, Denvir, \& Wiliam, 2008) was used to explore the average mathematical attainment gains of each set. Tests were conducted as pre- and post-tests with all pupils in October 2007 and July 2008. These were administered, following training, by the usual class teachers in lesson time with administration observed in two classes. Attainment data were collated in SPSS. Using formulae developed by Brown et al. (2008), mathematics 
age gains were calculated. These gains provided data within themselves across sets and were comparable with the gains and targets expected by the school (as shown in Table 1).

Descriptive and inferential statistics were applied with the understanding that parametric tests with this sample size carry limitations; hence particularly conservative tests, such as the Bonferroni post-hoc test, were used.

\section{Classroom observation}

This case-study draws on 6 formal observations of Set 4 although analysis involved comparison across the full data set. Observations were conducted as a non-participant observer. Each observation focussed on three focal-pupils within the context of the wider classroom activity. Field notes were written describing occurrences (e.g. interactions, activities) in real time, with plans, drawings and tables used to further document the observations. Examples of work and classroom resources were collated as appropriate. Following each observation, field-notes were annotated through a process of "incipient theorizing" (Jaworski, 1998, p. 119), forming a clear distinction between description and interpretation. Where feasible, pupil interviews (detailed below) were conducted immediately following formal observations allowing for participant collaboration.

\section{Interviews}

Interviews were used in addition to observations to "examine individuals' thoughts, feelings, and experiences, which are not easily observed" (Moore, Lapan, \& Quartaroli, 2012, p. 251). Individual pupil interviews were semi-structured using tasks adapted from Personal Construct Interviewing techniques. Focal-group interviews were semi-structured with a schedule and tasks - including a discussion of mathematical work - developed from earlier research by the author. Follow-up group interviews were used as a form of participant validation developing conversation around themes emerging from early analysis. All pupil interviews were conducted away from the classroom and developed as conversations with themes explored as 
brought up by the pupils. At the end of the research period all teachers were interviewed individually. Teacher interviews were semi-structured using a schedule developed over the course of the research from emerging themes. An adapted form of the pupil interview Personal Construct task was used to elicit teachers' constructs. All interviews were audiorecorded, transcribed and filed with task outcomes.

\section{Qualitative data analysis and selection}

All field-notes and transcripts were imported into a single NVivo project allowing for consistent coding and analysis. Data were open-coded drawing on constructivist grounded theory (Charmaz, 2006), looking for similarities and differences that revealed themselves on immersion in the data (Strauss \& Corbin, 1998). Codes were structured into trees prior to employing an axial-coding process. Salient concepts and relationships were identified through scree plots and matrix queries giving an indication of potentially important themes.

Themes emerging from the axial-coding in relation to the research questions of the wider study were drawn out and triangulated (see below) with other sources. Not an area under initial investigation, triage arose as a sub-theme within the wider data analysis and was interrogated further for the presentation of this case-study. Data related to educational triage fell across the 82 codes and four over-arching themes: constructing, enacting, experiencing and labelling ability. From the corpus of data appended to each main theme (e.g. pedagogic differences as a sub-level of the theme experiencing ability) extracts, often critical incidences, were selected which best illustrated the area under discussion. The initial categorization of these extracts arose from a grounded theory approach. The understandings and meanings behind these extracts were then interrogated with particular reference to Gee's stance on Discourse, viewing ability as a shared theory of goods distribution. 


\section{Reliability and validity}

Concerns are often raised about small-scale case-studies, such as this research report, and the limitations in what they can say beyond the individual case (e.g. Corcoran, Walker, \& Wals, 2004). Taking Avenue Primary as a telling-case situated within Gee's approach to Discourse aims to ameliorate this concern. The practice of creating a smaller group for the lowest attaining pupils - the basis of the arguments presented in this paper - has previously been documented across other research sites (Davies, Hallam \& Ireson, 2003) and is anecdotally reported as commonplace. Further, challenge to the practices documented at Avenue Primary did not occur despite this being a site where, if parental challenge was to occur, one would expect to see it. Given this, it is reasonable to suggest that an orthodoxy of ability works in such a way as to override potential challenge, with comparable practices and outcomes likely across educational sites employing similar practices.

Reliability and validity were key considerations throughout the data collection, analysis and presentation processes. Where possible, established instruments with known reliability and validity were used; in all cases instruments were extensively piloted. Across the analysis stages, quantitative and qualitative data were linked using methodological triangulation (Denzin, 1997) where data types were compared to determine if there was convergence, difference, or some combination. Participant validation through follow-up group interviews and inter-researcher scrutiny of coding use and application provided a proxy for the validity of the themes drawn from the data (Kurasaki, 2000). These measures resulted in a rigorous approach to a small-scale case-study whereby the reader can follow through the chain of evidence and its analysis and infer how it applies to the local context.

\section{Research Findings}

Teachers at Avenue Primary consciously engaged in a process of educational triage stated, in teacher interviews and general discussion with the Senior Management Team, as a response to Government accountability and a desire to raise the profile of the school in an area where 
parents were concerned about securing selective secondary school placements. For the purpose of this case-study two facets of Avenue Primary's triaging process are important: the enhanced resourcing of Set 3 who were on the cusp of achieving the expected outcomes in the national tests at the end of primary school and the allocation of the lowest attaining students to a small group (nine pupils) for mathematics. Unsurprisingly, all Set 3 pupils appear to have benefitted from their enhanced provision. What is surprising - and the focus of this paper - is that Set 4 pupils made lower gains than all other sets, considerably increasing the attainment gap between the lowest attaining pupils and their peers over the course of Year 6. This comes despite Set 4 experiencing smaller group instruction which could reasonably be expected to be beneficial. This paper explores how shared theories about ability, caught up within the practical complexities of providing small group instruction, led to practices which may have contributed towards the restricted mathematical attainment gains made by Set 4 .

\section{Impacts of educational triage on mathematical attainment}

Pupils sat pre- and post-attainment tests almost 10 months apart. The means and standard deviations for each administration and pupils' mathematical age gains (in years) for Sets 1-4 are shown in Table $3 .^{4}$

Table 3 here

The results for Sets 1-3 are not surprising and show what would be expected from the triaging process at Avenue Primary. On average, pupils in Set 1 and Set 2, who were already achieving at the desired outcome level and hence, through the triage process, did not receive special treatment, made gains respectively of just under, and just over, a year. Set 3 pupils, who received enhanced input, made higher gains equivalent to just over one year and four months. All pupils in Sets 1-3 achieved the output measure of at least Level 4 in their end of primary school national tests in mathematics. 
Set 4 made an average gain of seven months, less than the average gains made by all other sets. No pupil in Set 4 who took the national tests in mathematics at the end of primary school reached the Government Level 4 target. The attainment gap between Set 4 and Set 3 widened from 1.45 years at the beginning of Year 6 to 2.22 years at the end of Year 6, representing an increase of 0.77 years in the attainment gap over a period of just under ten months. Whilst parametric tests have inherent issues, particularly with small sample sizes, a conservative test gives evidence to suggest that these attainment differences are real ${ }^{5}$. The following sections examine what happened for Set 4 which may have contributed towards these outcomes.

\section{Group size}

Set 4 pupils in Year 6 at Avenue Primary were in a group of nine pupils (compared with 31 in Sets 1 and 2 and 17 in Set 3). Creating small groups for the lowest attaining pupils in mathematics was a strategy used in all year groups at Avenue Primary and in Year 6 at the second research site within the wider study. Further, creating small groups for lower-attaining pupils is documented in the literature (Davies, Hallam \& Ireson, 2003) and recognised by many teachers as common practice. Rationale for the use of small groups include "more individual attention and teacher interaction" (ibid., 2003, p. 52). However, it should be noted that research into group-size effects is fairly equivocal, particularly in terms of the causes of positive outcomes (e.g. Blatchford, Bassett, Goldstein \& Martin, 2003). The small teaching group for Set 4 at Avenue Primary had unintended consequences which may have impinged on pupils' mathematical learning and attainment gains.

\section{Teaching spaces and resources}

The small group size for Set 4 was made possible by creating more Year 6 mathematics sets (four) than Year 6 classes (three). Whilst achieving the aim of producing a small group, organisational issues arose as four sets could not be physically accommodated in three Year 6 
classrooms. Set 4 were not timetabled to a regular learning space and instead made use of infant (ages 3-7) classrooms, resource bases, derelict temporary classrooms (PortaKabins) and corridors. Movement to these spaces took time away from teaching and learning. Further, being physically located away from the Year 6 classrooms, pupils were required to walk through parts of the school such as nursery (ages 3-4) areas and infant corridors they would not normally frequent. On some occasions, their presence in these areas was challenged by school staff, requiring the pupils to defend their spatial location, and potentially inciting feelings of exclusion.

During some observations, Set 4 had to move during the lesson when the room was required by another class. The environments were often uncomfortable, with inappropriately sized furniture for Year 6 children and distracting, particularly where corridor spaces were used. I noted after one observation on a particularly warm day in a PortaKabin that the discomfort I had felt was also likely to be experienced by the pupils and may impact on their learning:

The learning resource base Set 4 often used was unavailable today. We wandered round the school trying to find somewhere else to have the lesson for 5-10 minutes. The lesson was conducted in a dusty cramped PortaKabin in the corner of the playground. Half the room was filled with old furniture. The sun was streaming into the unventilated PortaKabin and it quickly became very hot. I found it a very uncomfortable environment to work in and I suspect the pupils did too as they quickly removed sweaters and repeatedly asked for drinks or made excuses to leave the room, with most requests denied. The pupils were supposed to be working on individual worksheets on basic number fact recall $(12+7,3 \times 4$ etc. $)$ but these did not sustain their attention. (Research journal notes)

Whilst these notes are based on my perception of how the pupils may have felt and responded, written after a formal lesson observation, they suggest how weaker attainment may unintentionally be brought about through practices linked with a triaging process. Focussing attention on providing suitable resources for pupils in Sets 1-3 - with its positive outcomes - may restrict awareness of what is happening, or the consequences of this, for those pupils in Set 4 . Set 4 pupils appeared aware that their classroom environment impacted 
on their mathematics learning. Following a lesson observation in which the pupils had been required to move rooms during the lesson, I asked Samuel, in his interview, if this often happened:

Yeah, we go into the other room, cause when the year 1 comes they want the room we're in and we have to go to another room and it's just not helpful, like if you have been learning maths in one room, and you learnt it, if you have to move somewhere else new and you're not really good at maths it just, I get a feeling, I don't like that, it's harder. (Samuel, 04.03.08)

Samuel talked about the difficulty of continuing learning after the disruption of moving classrooms; observation would concur with this suggesting that pupils engaged with the mathematical tasks in a very limited manner after moving classrooms.

The lack of a consistent teaching space also had implications for access to mathematical resources. Sets 1-3, taught in Year 6 classrooms, had access to regular teaching paraphernalia including Interactive White Boards, 100-Squares and Number Lines, potentially making it easier for the teacher to respond to pupils' ideas and misconceptions. Set 4 were limited to what the teacher had planned for and could physically carry. Larger items of mathematical equipment were distributed amongst the Year 6 classrooms and readily shared; this was not an option for Set 4 who were often physically located far from the Year 6 base. In addition to lacking mathematical equipment, Set 4 also lacked regular classroom equipment. Set 4 pupils were observed attempting to measure with, or count along, rulers with missing graduations and using meter sticks in place of $30 \mathrm{~cm}$ rulers.

Teachers across the wider study noted that space restrictions impacted on their teaching of the lowest attaining groups. Mrs Jerrett, who taught Set 4 in Year 4 at Avenue Primary, confirms the issues observed and the pupils' perceptions of these:

In our group we could have done more get up and do except in that computer room there isn't a lot of space and you know in the corridor you're a bit constrained and a bit public as well because everyone is walking through. (Mrs Jerrett, 16.07.08)

Mrs Jerrett succinctly highlights a number of hidden implications of learning space allocation. She notes limits to the types of activities that can be undertaken, with limited 
space to engage in anything other than seated work. Further, she also suggests how lessons conducted in the corridor were not only disrupted by others walking through but also put the pupils on full view to the rest of the school. This illustrates Clark's (2002, p. 9) recognition that different learning spaces "can directly support or inhibit learning" yet space-allocation issues may not be seen as a direct consequence of ability-grouping practices.

\section{Teacher allocation}

The creation of more sets than classes also resulted in logistical issues with regards staffing. With only three Year 6 teachers at Avenue Primary, a regular Year 6 teacher was not available for all sets. When asked about teacher allocation, Avenue Primary teachers were clear about how this issue was resolved: "Usually we put the strongest teacher in the Cuspgroup [Set 3] or in the most able group [Set 1], they're the main two" (Mr Iverson, 16.07.08). The teaching of Set 4 was shared between Mr Leverton, a floating teacher employed by the school to teach classes as the need arose, for three lessons a week, and a Higher Level Teaching Assistant (introduced under the 2003 Teacher Workload Agreement, HLTAs are not qualified teachers but may take lessons) for two lessons a week. Mr Leverton talked at length, both in his interview and informally during the year, about his concern that he had seen in all year groups at Avenue Primary and across other primary schools the lowest sets being allocated the weakest or newest teachers or being assigned to work with a teaching assistant. This concern, particularly in relation to teaching assistants taking the lowest attaining pupils, is also highlighted in the literature by Webster et al. (2011).

Inconsistencies in teacher allocation did not go unnoticed by pupils. When asked in a group interview to describe their mathematics lessons, Year 6 Set 4 pupils spontaneously drew a comparison with what they felt Set 3 was like, focussing on resources, including staffing:

Peter: Mr Quinton's set [Set 3] are Level 4 and Mr Leverton's we're like 3 ... Well it's not fair. In Mr Quinton's group you get treated differently. 
James: It's soooo different. They don't care about us being happy, we don't have nothing, no resources in lessons, nothing. We don't have nothing to use.

Samuel: We all need helpers in our class, [Set 3] have got helpers, but we haven't got no helpers, it's really different. (Focal-group interview, 06.01.2008)

Whilst the pupils' discussion is based in both fact (they knew there were teaching assistants in Set 3) and opinion (their belief that the teachers did not care about them being happy), it shows that they were aware of a difference in the staff allocated to them. In individual interviews pupils also used similar language with Peter having previously talked about money not being spent on them and staff not wanting them to be happy, suggesting the importance of these issues to the pupils. Further, Peter suggests that Set allocation is related to the Levels they may attain in the mathematics national tests at the end of primary school and that this has an impact on the teacher and teaching received. Whilst Peter views this as being "not fair", the facts of limited resources and a lack of additional teaching assistants were evident in the school's policies and in the lesson observations.

\section{Group dynamics and assumptions}

Whilst space and resource distribution represent unintended - or un-thought through restraints on mathematical attainment, restraints may arise directly from the small group size. In a size-restricted group there is a tendency towards teacher-pupil rather than managed pupil-pupil interactions. This appeared to be characteristic of interactions within Year 6, Set 4 at Avenue Primary reflecting the "poor interactive dynamics" also found in secondary school research (Pedder, 2006, p. 228). This led to an over-reliance on the teacher for the 'correct' answer, possibly restricting pupils' development of self-help / self-correction strategies and supporting a view of mathematics dominated by achieving one correct solution.

Mathematical pedagogy in Set 4 was limited through assumptions about ability and the learning approaches of the lowest attaining pupils as shared, and hence perceived as 'right', within the teacher Discourse Community. Such shared Discourse served to further normalise taken for granted meanings and outcomes caught up within many ability-grouping 
practices. A triage process resulted in grouping the lowest attaining pupils together in a small, low-priority group and thus teachers were not placed in the position of having to challenge these assumptions or explore provisions outside of what they saw as suitable for Set 4. Unlike Sets 1-3, Set 4 did not receive a curriculum structured around the methods and content of the Primary Framework (the national framework for the content and methods of teaching mathematics in place at the time of the study). Instead, as evidenced through lesson observations and discussions with Mr Leverton in which he shared his planning and resources, work in Set 4 often took the form of low-level repetitive worksheets completed on an individual basis. Often these worksheets came from Year 1 and 2 (ages 5-7) resource books. Rationale for using low-level work included allowing pupils to experience success and the need to keep numbers small so that manipulatives (e.g. counters) could be used to support numerical work. Assumptions abound that manipulatives are only suitable for the lowest attaining pupils with their use most commonly occurring in the lowest sets (Oakes, 1982). All teachers talked about the use of counting materials being supportive. They exhibited a lack of awareness of the possible implications for pupils' mathematical development where an insistence on the use of cubes restricted movement between representations and reduced possibilities to work with larger numbers through the sheer time involved in counting out cubes. The literature suggests that consistently using small numbers and cubes forces pupils into using less sophisticated counting models - counting out cubes and counting all the cubes together - rather than having the opportunity to learn to work, for instance, with derived facts. This leads to pupils doing more, if unhelpful, mathematics, potentially restricting their mathematical development (Gray \& Tall, 1994). Further, a low-level manipulative-led curriculum may have restricted pupils' mathematical gains through lack of preparation for the national tests. Lessons in Sets 1-3 in Year 6 were dominated by revision, practice papers, and mock tests, as is well-documented in the literature, was widely discussed by teachers in 
interviews and was evident across both research sites. Conversely, Set 4 pupils, who through the triage process were separated out as a group not expected to attain the Government Level 4 target, received no preparation and some pupils, including Samuel in this case-study, were dis-applied from the tests.

Shared assumptions about Set 4 pupils' behaviour also restricted the pedagogic approaches taken. Tasks were given which were most likely to keep the pupils on-task and engaged in individual activities, reducing the potential for behavioural issues arising. Whilst mathematical discussion and collaborative work is well-reported as being limited in all mathematics classrooms, Mr Leverton made a conscious effort to restrict this on the basis of beliefs that Set 4 pupils were unable to engage in discussion in a mature manner and did not possess collaborative working skills. As such, much class-work was completed individually with the expectation that pupils would converse only with the teacher. In their individual interviews, two of the three focal-pupils, without prompt, discussed not being allowed to talk when asked what their mathematics lessons were like. Whilst they both admitted - as did pupils in other sets - that they often wanted to talk about non-mathematical issues they noted that they were restricted in all talk, including mathematical talk, which they felt was because the teacher would think they were misbehaving. Evidence of the lack of discussion of work was observed in many lessons with one observation suggesting how limits on mathematical talk may also inadvertently limit pupils' mathematical progression:

Samuel and Saul are working (individually) on a worksheet on division by two (i.e. 16 $\div 2$ ). They are using cubes to get the answers. Samuel puts his cubes into groups of two. He notices that Saul is putting his cubes into two groups. Samuel tells Saul he is doing it wrong, which leads to an animated conversation between the boys. This discussion is interrupted by the teacher [Mr Leverton] who admonishes them for the noise they are making and tells them they must work individually. (Observation notes, 08.03.2008)

In this observation, Samuel and Saul were actually engaged with an important mathematical concept involving two models of division. However, inexperience in teaching Year 6 and the belief that any dispute occurring with low-ability labelled pupils must be non-mathematical 
may have led to Mr Leverton missing an opportunity to engage the pupils in this mathematical concept. Opportunities for potentially rich discussion such as this were observed to be rare given the types of tasks presented to pupils and the restricted methods they were required to use to complete work. As such it would seem important that any opportunities for discussion are fully utilised, yet assumptions about these pupils, based on beliefs about ability, may be leading to missed opportunities.

\section{Discussion}

This case-study, drawing on an unanticipated theme arising from a wider study, documents how some consequences of an apparently supportive practice - the use of small group sizes for the lowest attaining pupils - may be considered a contributory factor towards lower mathematical gains and a widening attainment gap. The paper illustrates how staff at Avenue Primary, caught up in a process of 'gaming the system', made decisions about the distribution of educational resources. These decisions are grounded in shared meaning making - in this case meanings related to ability (in its widest sense - teachers constructed ability to include notions of, for example, behaviour, attitude, and potential) - developed within the Discourse Communities teachers inhabit. Whilst the school's practices had the intended consequence of pushing those pupils in Set 3 up to a Level 4, the implications for Set 4 were unexpected and to an extent, unseen.

Teachers at Avenue Primary were aware of their use of triage. Members of senior management talked about the pressure to maximize outputs as in Mr Iverson's interview extract arising from a discussion of the use of assessment across the school:

We're accountable to parents, we're accountable to the local authority, Ofsted and the Government and they work with levels and as we still have the crazy system of testing in key stage two that's the way that we are judged so we have to go down that road because that's the currency that the Government check that schools are working properly. I think that whole system is ludicrous, and actually there's much better ways of assessing and reaching standards rather than narrowing the curriculum to meet this coverage of curriculum by test, it's all about the curriculum, targets, and partly trust as well and it's about trusting teachers to do their job, also trusting head teachers to check that teachers do their jobs and spending more time on learning rather than maybe 
narrowing the curriculum to a particular test so that the school can be perceived to reach a certain standard which is very very narrow. (Mr Iverson, 16.07.08)

Mr Iverson notes that, although he sees the system as "ludicrous", it exerts a powerful influence. Schools, such as Avenue Primary, appear to be in a position where they have little choice but to play the accountability game. There was far less awareness of both the assumptions underlying, and the unexpected consequences of, the practices put in place to respond to these pressures. The results for Set 3 would be viewed as a success whilst the limited attainment of Set 4 could be accounted for through shared beliefs about potential and assumptions that these pupils were working at the peak of their capability.

It is important to emphasise that the teachers in this study were not deliberately acting in ways contrary to effective primary school teaching, but were responding to the consequences of a common and expected classroom practice. Their practices, based on shared understandings of ability (as a 'Big D' Discourse), were enacted to provide a best fit in addressing Governmental pressures to maximize the numbers of pupils achieving Level 4 (through enhanced provision for Set 3) and supporting the lowest mathematically attaining pupils (through a small group size for Set 4). Where teachers were aware of imperfections in these practices they sought to ameliorate these, seeking out, for example, alternative learning spaces. However, the enacted practices impacted on Set 4 attainment in unexpected ways. Teachers need space to explore these unexpected outcomes, challenging the shared assumptions developed within their Discourse Communities. Developing such space has the potential to inject dissonance, leading to a questioning of current shared theories of goods distribution which triage relies on for its continuation.

The challenge to disrupt shared meaning-making around ability within Discourse Communities is applicable beyond the specifics of this case-study and Avenue Primary. As noted earlier, Avenue Primary sits as a telling case. Whilst the specific events documented are particular to the school, the lessons to be learnt go beyond this individual case. Shared 
theories in relation to ability will be both local and national and the related literature emphasises that similar practices - such as the creation of small groups - occurs in other locations. The details of this report allow the reader to make their own inferences about the applicability to their local context, both people and situations. There is the potential to challenge the shared meanings and assumptions under which the orthodoxy of ability persists. This could subsequently support the mathematical development of all pupils, avoiding the (potentially unstable) boosting of particular pupils whilst disrupting practices which may carry unintended consequences for some of the most vulnerable mathematics learners.

\section{Acknowledgements}

This research would not have been possible without the willing participation of the schools, teachers and pupils. The study was funded by a studentship from the Economic and Social Research Council (award number: PTA-031-2006-00387).

\footnotetext{
${ }^{1}$ All names within this paper are pseudonyms.

${ }^{2}$ Ability is presented without quotation marks to aid readability. The reader should assume that the legitimacy of the concept is continually questioned.

${ }^{3}$ The study originally had Rhiannon as a focal-pupil. She was moved, due to school reorganisation, to Set 3. James was added to the focal-pupils for group-interviews.

${ }^{4} n$ represents the number of pupils completing both pre- and post- tests and hence is lower than the total number of pupils in Year 6.

${ }^{5}$ An ANOVA test suggests significant differences between the gains made by each set, $\mathrm{F}(3,67)=4.503, p=0.006$. A Bonferroni post-hoc test, suitable for small numbers of comparisons and providing control over Type 1 errors (Field, 2005), shows that the differences between the gains made by Set 3 and Set 4 are significant at $p=0.01$.
} 


\section{References}

Blatchford, P., Bassett, P., Goldstein, H. and Martin, C. (2003). Are class size differences related to pupils' educational progress and classroom processes? Findings from the institute of education class size study of children aged 5-7 years. British Educational Research Journal, 29, 709-730. doi:10.1080/0141192032000133668

Boaler, J. (1997). Experiencing school mathematics: Teaching styles, sex and setting. Buckingham: Open University Press.

Booher-Jennings, J. (2005). Below the bubble: "Educational triage" and the Texas accountability system. American Educational Research Journal, 42, 231-268. doi:10.3102/00028312042002231

Brown, M., Askew, M., Hodgen, J., Rhodes, V., Millett, A., Denvir, H., \& Wiliam, D. (2008). Progression in numeracy ages 5-11: Results from the Leverhulme longitudinal study. In A. Dowker (Ed.), Mathematical Difficulties: Psychology and intervention (pp. 85-108). Oxford: Elsevier.

Charmaz, K. (2006). Constructing grounded theory: A practical guide through qualitative analysis. London: Sage.

Clark, H. (2002). Building education: The role of the physical environment in enhancing teaching and research. London: Institute of Education, University of London.

Corcoran, P., Walker, K., \& Wals, A. (2004). Case studies, make-your-case studies, and case stories: a critique of case-study methodology in sustainability in higher education. Environmental Education Research, 10, 7-21. doi:10.1080/1350462032000173670

Davies, J., Hallam, S., \& Ireson, J. (2003). Ability groupings in the primary school: Issues arising from practice. Research Papers in Education, 18, 45-60. doi:10.1080/0267152032000048578

Denzin, N. K. (1997). Triangulation in educational research. In J. Keeves (Ed.), Educational research, methodology, and measurement: An international handbook (2nd ed., pp. 318-322). Oxford: Elsevier Science.

Field, A. (2005). Discovering statistics using SPSS (2nd ed.). London: Sage.

Gee, J. P. (1999). An introduction to discourse analysis. London: Routledge.

Gee, J. P. (2008). Social linguistics and literacies: Ideology in discourses (3rd ed.). London: Routledge.

Gewirtz, S., \& Cribb, A. (2009). Understanding education. A sociological perspective. Cambridge: Polity Press

Gillborn, D., \& Youdell, D. (2000). Rationing education: Policy, practice, reform and equality. Buckingham: Open University Press.

Gray, E., \& Tall, D. (1994). Duality, ambiguity, and flexibility: A "proceptual" view of simple arithmetic. Journal for Research in Mathematics Education, 25, 116-140. Retrieved from: http://www.jstor.org/stable/749505

Hallam, S., \& Parsons, S. (2013). Prevalence of streaming in UK primary schools: evidence from the Millennium Cohort Study. British Educational Research Journal, 39, 514544. doi:10.1080/01411926.2012.659721

Howe, M. (1996). Concepts of ability. In I. Dennis \& P. Tapsfield (Eds.), Human abilities:Their nature and measurement (pp. 39-48). Mahwah, NJ: Lawrence Erlbaum Associates.

Jaworski, B. (1998). The centrality of the researcher: Rigor in a constructivist inquiry into mathematics teaching. In A. Teppo (Ed.), Qualitative research methods in mathematics education (pp. 112-127). Reston, Virginia: NCTM.

Keenan, D., \& VanHorn, R. (1979). Educational Triage. The Phi Delta Kappan, 60. 
Kulik, C., \& Kulik, J. (1982). Research synthesis on ability grouping. Educational Leadership, 39, 619-621. Retrieved from:http://www.ascd.org/ASCD/pdf/journals/ed_lead/el_198205_kulik.pdf

Kurasaki, K. S. (2000). Intercoder reliability for validating conclusions drawn from openended interview data. Field Methods, 12, 179-194. doi:10.1177/1525822X0001200301

Marks, R. (2012). Discourses of ability and primary school mathematics: Production, reproduction and transformation. Unpublished PhD Thesis. King's College London.

Marks, R. (2013). 'The Blue Table Means You Don't Have a Clue': The persistence of fixedability thinking and practices in primary mathematics in English schools. Forum, 55, 31-44. Retrieved from: http://dx.doi.org/10.2304/forum.2013.55.1.31

Mitchell, J. C. (1984). Case studies. In R. F. Ellen (Ed.), Ethnographic research: A guide to general conduct (pp. 237-241). London: Academic Press.

Moore, T., Lapan, S., \& Quartaroli, M. (2012). Case study research. In S. Lapan, M. Quartaroli \& F. Riemer (Eds.), Qualitative research: An introduction to methods and designs (pp. 243-270). San Francisco: Jossey-Bass.

Neal, D., \& Schanzenbach, D. W. (2010). Left behind by design: Proficiency counts and testbased accountability. The Review of Economics and Statistics, 92, 263-283. doi:10.1162/rest.2010.12318

Oakes, J. (1982). The reproduction of inequity: The content of secondary school tracking. The Urban Review, 14, 107-120. doi:10.1007/BF02174647

Pedder, D. (2006). Are small classes better? Understanding relationships between class size, classroom processes and pupils' learning. Oxford Review of Education, 32, 213-234. doi:10.1080/03054980600645396

Solomon, Y. (2007). Experiencing mathematics classes: Ability grouping, gender and the selective development of participative identities. International Journal of Educational Research, 46, 8-19. doi:10.1016/j.ijer.2007.07.002

Strauss, A., \& Corbin, J. (1998). Basics of qualitative research: Techniques and procedures for developing grounded theory (2nd ed.). London: Sage.

Webster, R., Blatchford, P., Bassett, P., Brown, P., Martin, C., \& Russell, A. (2011). The wider pedagogical role of teaching assistants. School Leadership and Management, 31, 3-20. doi:10.1080/13632434.2010.540562

Wiliam, D., \& Bartholomew, H. (2004). It's not which school but which set you're in that matters: the influence of ability grouping practices on student progress in mathematics. British Educational Research Journal, 30, 279-293. doi: 10.1080/0141192042000195245 


\begin{tabular}{|l|l|l|l|}
\hline Set & Number of pupils & $\begin{array}{l}\text { Attainment at } \\
\text { beginning of Year 6 }\end{array}$ & $\begin{array}{l}\text { Levels attained at } \\
\text { end of Year 6 }\end{array}$ \\
\hline 1 & 31 & Level 4/5 & Level 5 \\
\hline 2 & 31 & Level 4 & Level 4/5 \\
\hline 3 & 17 & Level 3 & Level 4 \\
\hline 4 & 9 & Below Level 3 & Level 3 and below \\
\hline
\end{tabular}

Table 1: Set composition and expected attainment ranges

\begin{tabular}{|c|c|c|}
\hline Research Method & Main Study & Case-Study \\
\hline Attainment tests & $\begin{array}{l}284 \text { pre-tests } \\
284 \text { post tests }\end{array}$ & $\begin{array}{l}88 \text { pre-tests } \\
88 \text { post-tests } \\
\text { (Year } 6, \text { Avenue Primary) }\end{array}$ \\
\hline Attitudinal questionnaires & $\begin{array}{l}284 \text { pre-tests } \\
284 \text { post tests }\end{array}$ & Not included in case-study \\
\hline Classroom observation & $\begin{array}{l}48 \text { formal observations } \\
\text { (two per set/class per term) }\end{array}$ & $\begin{array}{l}6 \text { formal observations } \\
\text { (Set 4, Year 6, Avenue } \\
\text { Primary) }\end{array}$ \\
\hline Individual pupil interviews & $\begin{array}{l}24 \\
\text { (one per focal-pupil) }\end{array}$ & $\begin{array}{l}3 \\
\text { (one per focal-pupil, Set 4, } \\
\text { Year 6, Avenue Primary) }\end{array}$ \\
\hline Group pupil interviews & $\begin{array}{l}16 \\
\text { (Groups of three pupils } \\
\text { interviewed twice) }\end{array}$ & $\begin{array}{l}2 \\
\text { (Set 4, Year 6, Avenue } \\
\text { Primary focal-pupils, } \\
\text { interviewed twice) }\end{array}$ \\
\hline $\begin{array}{l}\text { Individual teacher } \\
\text { interviews }\end{array}$ & $\begin{array}{l}8 \\
\text { (Each teacher interviewed } \\
\text { once) }\end{array}$ & $\begin{array}{l}2 \\
\text { (Set 4, Year 6, Avenue } \\
\text { Primary teacher and } \\
\text { Deputy Head) }\end{array}$ \\
\hline
\end{tabular}

Table 2: Main-study and case-study research design

\begin{tabular}{|c|c|c|c|c|c|c|c|}
\hline & & \multicolumn{2}{|c|}{$\begin{array}{c}\text { Pre-test } \\
\text { Mathematics Age }\end{array}$} & \multicolumn{2}{c|}{$\begin{array}{c}\text { Post-test } \\
\text { Mathematics Age }\end{array}$} & \multicolumn{2}{c|}{$\begin{array}{c}\text { Mathematics Age } \\
\text { Gain (years) }\end{array}$} \\
\hline Set & n & Mean & s.d. & Mean & s.d. & Mean & s.d. \\
\hline 1 & 25 & 12.67 & 0.59 & 13.50 & 0.37 & 0.83 & 0.49 \\
\hline 2 & 24 & 10.82 & 0.60 & 11.89 & 0.65 & 1.07 & 0.46 \\
\hline 3 & 13 & 9.76 & 0.60 & 11.11 & 0.59 & 1.36 & 0.69 \\
\hline 4 & 9 & 8.31 & 0.46 & 8.89 & 0.91 & 0.59 & 0.65 \\
\hline
\end{tabular}

Table 3: Avenue Primary Year 6 mathematics attainment gains 